\title{
Tingkat Kemampuan Mengajar Kelas Bertaraf Internasional Guru Al Azhar Melalui TKT (Teaching Knowledge Test) pada Tingkat SD, SMP, dan SMA
}

\author{
Ria Herwandar* \\ Program Studi Sastra Inggris, Fakultas Sastra, \\ Universitas Al Azhar Indonesia, Jalan Sisingamangaraja, Jakarta 12110 \\ *Penulis untuk Korespondensi : ria_herwandars@uai.ac.id
}

\begin{abstract}
Abstrak - Teaching Knowledge Test merupakan program yang sangat efektif bagi guru-guru Al Azhar sebagai senjata untuk mengajar di program sekolah bertaraf internasional (SBI). Penelitian ini diawali dengan pelatihan 30 jam dan ujian akhir yang diselenggarakan langsung oleh Cambridge University. Penelitian ini menggunakan teori perolehan Bahasa ke 2, membahas materi 3 modul pola pembelajaran dan pengajaran dan sejauh mana keberhasilan para guru dalam memahami pelatihan TKT ini. Temuan hasil penelitian akan menjadi ukuran bagaimana harus menanggulangi kelemahan yang ada. Tujuannya adalah agar program SBI dapat berjalan sempurna dan efektif sehingga mampu meningkatkan kualitas belajar mengajar sesuai standar internasional. Apabila standar internasional telah dimiliki maka sekolah Al Azhar mampu menciptakan kualitas guru dan murid yang sempurna.
\end{abstract}

Abstract - Teaching Knowledge Test is an effective programme for teachers of Al Azhar, as a tool to equipt teachers in teaching under the program of international school known as SBI. The research has started by the implementation of 30 hour of TKT training and followed by an examination conducted by the Cambridge University. The research is basing on second language acquisition and has discussed the three Modu;es of teaching and learning and how far can the modules be understood by the teachers. The result finding will become the measurement of how the weakness should be overcome. The purpose of this research is to enable the SBI operates perfectly and effectively and produces qualified teaching and learning environment inline with the international standard. Once the international standard has been achieved, Al
Azhar school would have been able to create qualified teachers and student perfectly.

Keywords - Teaching Knowledge Test, Module, Al Azhar Teachers

\section{PENDAHULUAN}

\subsection{Latar Belakang}

$\mathrm{B}$ erdasarkan buku panduan penyelenggaraan Program Rintisan SMA Bertaraf Internasioanl yang diterbitkan oleh Departemen Pendididkan Direktorat Jendral Management Pendidikan Dasar dan Menengah Direktorat Pembinaan Sekolah Menegah Atas tahun 2009, dijelaskan bahwa era globalisasi ditandai dengan persaingan ketat di bidang teknologi, management dan sumber daya manusia (SDM).. Ke tiga faktor ini dapat ditingkatkan kualitasnya melalui pendidikan yang berkualitas. Dengan kebutuhan untuk memperbaiki kualitas pendidikan nasional maka dikeluarkan Undang-undang Republik Indonesia No 20 tahun 2003 tentang Sistim Pendidikan Nasional sebagai dasar hukum penyelenggaraan dan reformasi sistim pendidikan nasional. Pada pasal 50 ayat 3 menyatakan bahwa "Pemerintah dan/atau Pemerintah Daerah menyelenggarakan sekurangkurangnya satu satuan pendidikan pada semua jenjang pendidikan untuk dikembangkan menjadi satuan pendidikan yang Bertaraf Internasional" Keputusan ini sejalan dengan visi dan misi pendidikan nasional yang menekankan bahwa pendidikan nasional harus mampu mengembangkan manusia Indonesia yang berkualitassehingga mampu dan proaktif menjawab tantangan zaman yang selalu berubah dengan cepat. Pendidikan harus mampu menciptakan manusia yang dapat 
bersaing di tingkat regional, nasional, dan internasional.

Tujuan khusus Program Rintisan SMA Bertaraf Internasional antara lain adalah agar siswa mampu menguasai ilmu pengetahuan dan teknologi; mampu menggunakan bahasa Indonesia dan Inggris dengan baik dan benar; berdaya saing melanjutkan pendidikan di luar negeri; mengikuti sertifikasi internasional; dan meraih medali tingkat internasional.

Dari sudut kepentingan sekolah sebagai penyelenggara pendidikan bertaraf internasional maka beberapa kriteria harus dilaksanakan. Beberapa persyaratan antara lain: Sekolah tersebut harus terakreditasi $\mathrm{A}$, memiliki tenaga pengajar fisika, kimia, biologi, matematika dan mata pelajaran lainnya yang berkompeten dalam menggunakan ICT dan pengantar bahasa Inggris.. Sekolah harus memiliki sarana prasarana yang memenuhi standar untuk menunjang proses pembelajaran bertaraf internasional dengan memiliki tiga laboratorium IPA ( Fisika,Kimia dan Biologi), perpustakan, akses internet, web sekolah dan laboratorium computer. Kriteria yang diwajibkan diperkuat dengan makna atau pengertian dari Sekolah Bertaraf Internasional seperti yang tercantum dalam buku panduan yang diterbitkan Departemen Pendidikan. Sekolah Bertaraf Internasional adalah satuan pendidikan yang dikelola dengan menggunakan Standar Nasional Pendidikan (SNP) dan diperkaya dengan standar salah satu Negara anggota Organisation for Economic Co-operation and Development (OECD) dan/ atau Negara maju lainnya.

Sekolah Al Azhar di Jakarta mencoba mematuhi persyaratan Program Rintisan SMA Bertaraf Internasional. Sarana prasaran terus menerus diperbaiki. Dari segi SDM, telah diselenggaran berbagai kursus bahasa bagi para guru terutama di bidang mata pelajaran Fisika, Matematika,Kimia, Biologi dan bahasa Inggris. Standar pendidikan luar negeri yang di pakai adalah pendidikan Cambridge. Beberapa kelas dibawah naungan bilingual class sudah menerapkan pengajaran mata pelajaran diatas dalam bahasa Inggris. Lebih jauh, Pimpinan Yayasan Pendidikan Al Azhar merasa bahwa pengembangan program pendidikan bertaraf internasional ini harus secara menyeluruh diterapkan mulai di tingkat SD, SMP dan SMA agar terjadi kesinambungan yang konsisten. Apabila di tingkat SMA menggunakan pola pendidikan Cambridge IGCSE, maka ditingkat SD program yang diterapkan adalah Primary Cambridge Education. Perubahan yang terjadi di tingkat SD sampai dengan SMA tentu menjadi suatu pekerjaan yang cukup besar yang harus dikerjakan oleh sekolah sekolah Al Azhar di Jakarta.

\subsection{Pembatasan Masalah}

Dengan adanya perubahan dalam memperbaiki pendidikan kearah internasional tentu banyak yang harus dilakukan. Salah satu kegiatan menuju sekolah bertaraf internasional,(SBI) adalah memberbaiki kualitas kemampuan para guru dalam menyajikan mata pelajaran dalam bahasa Inggris di kelima mata pelajaran diatas. Disamping diberikan pengarahan cara mengajar Fisika, Matematika biologi, dan Kimia dalam bahasa Inggris, para guru juga diberi kursus bahasa Inggris Dasar dan Toefl. Kursus yang paling diminati para guru adalah kursus Teaching Knowledge Test. Para guru yang telah memilik kemampuan bahasa Inggris yang baik berdasarkan tes TOEFL yang mereka capai, diberikan kursus yang didanai yayasan $\mathrm{Al}$ Azhar. Mereka yang mencapai TOEFL skor 400 dapat mengikuti kursus Teaching Knowledge Test yang akan mengukur kemampuan mereka dalam mengajar yang efektif dalam bahasa Inggris. Untuk mengikuti pelatihan Teaching Knowledge Test diperlukan memiliki bahasa Inggris yang baik agar mampu menyerap ilmu kepengajaran dan mampu menyelesaikan ujian pada akhir pelatihan. dengan demikian, para peserta harus memiliki paling sedikit TOEFL 400. Di akhir pembelajaran mereka akan mendapat sertifikat yang dapat disamakan sebagai sertifikasi guru. Sertifikat TKT merupakan sertikat mengajar bertaraf Internasional dari Cambridge University yang telah diakui dunia, sehingga, seorang guru apabila telah memiliki sertifikat dengan nilai baik, dapat melamar pekerjaan sebagai pengajar di negaraa manapun.

Masalah yang dihadapi para guru adalah bahwa pertama, mereka dituntut untuk segera siap mengajar dalam bahasa Ingris dalam bidang mata kuliah Matematika , Fisika, kimia, Biologi dan Bahasa Inggris sesuai dengan kurikulum Cambridge. Ke dua, proses peningkatan kemampuan berbahasa Inggris menyita waktu yang cukup lama. Walaupun berbagai kursus diberikan, mereka masih mendapat kesulitan yang cukup besar. Kendala lain adalah tingkat kesibukan para guru yang dapat menghambat proses belajar 
mereka. Sementara mengajar mata pelajaran khusus memerlukan tingkat kemahiran berbahasa yang tinggi supaya mampu menjelaskan topik bahasan dengan jelas dan lugas. Kesulitan terberat adalah mengikuti standar pendidikan Cambridge yang sudah sangat baku dan terukur kualitasnya memberikan beban yang lebih besar bagi para guru. Oleh sebab itu, pelatihan Teaching Knowledge Test diberikan agar para guru dibekali strategi mengajar dalam bahasa Inggris.

\subsection{Rumusan Masalah}

Penelitian ini berkaitan dengan masalah yang dihadapi para guru SBI Al Azhar baik dalam mata pelajaran bahasa Inggris, Matematika, Fisika, Biologi dan Fisika, berdasarkan hasil wawancara dan pelatihan informal. Kesulitan yang mereka hadapi adalah sebagai berikut;

1) Mereka sudah memahami mata pelajaran yang harus diajarkan dalam bahasa Inggris, namun tidak mampu menyampaikan kepada murid dengan benar.

2) Mereka tidak memiliki dasar dasar pengajaran formal untuk program SBI berkaitan dengan pemerolehan bahasa ke dua.

3) Mereka tidak memiliki kemampuan mengembangkan pengajaran dan pembelajaran yang mandiri di dalam kelas.

4) Mereka memiliki tingkat kemampuan bahasa Inggris yang berbeda beda.

\subsection{Tujuan Penelitian}

Tujuan penelitian ini adalah untuk membuat pemetaan kemampuan para guru Al Azhar dalam memahami ilmu kebahasaan, pembelajaran dan pengajaran yang di sebut Teaching Knowledge Test sebagai alat bantu atau pendamping ketika harus mengajar mata pengajaran dibidang bahasa Inggris itu sendiri sebagai bahasa ke dua, matematika, Fisika, Biologi, dan Kimia dalam bahasa Inggris. Pemetaan kemampuan akan dilihat dari tiga unsur yakni:

1) Pemahaman tentang bahasa dan latar belakang belajar dan mengajar bahasa Inggris sebagai bahasa ke dua.

2) Pemanfaatan sumber sumber bahan ajar dan perencanaan pengajaran secara sistematis

3) Mengelola proses belajar dan mengajar di kelas dan penggunaan bahasa instruksional yang baku dalam bahasa Inggris

\subsection{Manfaat Penelitian}

Hasil penelitian Teaching Knowledge Test yang dilaksanakan oleh para guru Al Azhar dapat memberikan manfaat sebagai berikut:

1) Bagi pimpinan dan para guru $\mathrm{Al}$ Azhar

Dapat dengan mudah menganalisis tingkat kemahiran dan pengetahuan ataupun kekurangan dalam menyelenggarakan proses pembelajaran SBI. Para guru juga dapat secara individu dan mandiri mengembangkan sendiri tingkat kemahiran sesuai dengan kriteria yang tercermin dalam ke tiga module dalam Teaching Knowledge Test. Panduan yang meruju pada pola silabus dan kurikulum Cambridge ini menjamin kualitas lulusan SBI setelah dilaksanankan sesuai prosedur pembelajaran sehingga standar kualitas lulusan murid SBI sama dengan lulusan Cambridge di seluruh dunia.

2) Bagi Mahasiswa Fakultas Sastra dan Peneliti Penelitian ini dapat digunakan sebagai tambahan informasi ketika mahasiswa ingin memberdalam keilmuan dalam mengajar bahasa Inggris sebagai pembelajaran bahasa kedua. Bagi pemerhati dan pengamat SBI, informasi ini dapat menjadi informasi tambahan dalam memformulasi percepatan pembelajaran program SBI

\section{KERANGKA TEORI/TINJAUAN PUSTAKA}

\subsection{Pengertian Bahasa}

Pembahasan pemerolehan bahasa kedua erat kaitannya dengan pemahaman apa itu bahasa, pembelajaran dan pengajaran secara umum. Menurut Ron Schollon (2004) yang dikutip Douglas Brown (2008:6) bahasa bukanlah sesuatu yang datang dalam 'unit unit yang dikemas rapi'dan merupakan fenomena yang melibatkan banyak faktor, kompleks dan senantiasa berubah. Brown (2008:6) merangkum bahasa itu sistematis dipakai manusia untuk berkomunikasi. Bahasa dikuasai oleh semua orang dalam cara yang sama; bahasa dan pembelajaran bahasa sama sama mempunyai karakteristik universal.

\subsection{Pengertian Pembelajaran dan Pengajaran}

Mengenai definisi pembelajaran, Brown mendata dari berbagai kamus kontemporer sebagai 
penguasaan atau pemerolehan pengetahuan tentang sesuatu subjek atau sebuah keterampilan dengan belajar, pengalaman, atau instruksi. Lebih jauh seorang psikolog mendefinisikan pembelajaran sebagai 'sebuah perubahan dalam diri seseorang yang disebabkan oleh pengalaman' Slevin (2003) yang dikutip oleh Douglas Brown (2008:8).

Sementara definisi pengajaran adalah menunjukkan atau membantu seseorang mempelajari cara melakukan sesuatu, memberi instruksi, memandu dalam pengkajian sesuatu, menyiapkan pengetahuan, menjadikan tahu atau paham (brown, 2008: 8).

\subsection{Mazhab Pemikiran dalam Pemerolehan Bahasa Kedua.}

Kesepakatan yang dianut para linguis dan peneliti SLA (Second language Acquisition) mengenai bahasa dan pemerolehannya walaupun ada persamaannya namun penangannanya berbeda sesuai dengan perkembangan zamannya. Hal tersebut terpaparkan dalam bentuk tiga mazhab pemikiran dibidang linguistic dan psikologi sampai derajat tertentu secara historis (Brown, 2008:9), yakni:

\section{Linguistik Struktural dan Psikologi}

Behavioristik (1940-1950) Pengusung mazhab structural atau deskriptif adalah Leonard Bloomfield, Edward Sapir, Charles Hockett, Charles Fries dan lainnya mementingkan pengamatan ilmiah yang ketat terhadap bahasa bahasa manusia.Menurut kaum strukturalis tugas linguis adalah mengamati dan menjelaskan bahasa dan mengenali karakteristik structural bahasa tersebut.Gagasan yang utama adalah bahwa bahasa bisa dibongkar pasang menjadi kepingan kepingan atau unit unit kecil dan unit unit kecil ini dapat dijelaskan secara ilmiah, dikontraskan dan disusun lagi menjadi bentuk yang utuh (2008:10)

2. Linguistik Generative dan Psikologi Kognitif (1960-1980an) Chomsky dan pengikutnya mengatakan bahwa bahasa manusia tidak bisa di teliti semata mata dalam lingkup stimulus dengan respon hanya berdasarkan data mentah yang dikumpulkan di lapangan (Brown, 2008:11). Linguistik generative tidak hanya tertarik pada mendeskripsikan tingkat kecukupan deskritif bahasa tetapi juga berusaha mencapai tingkat kecukupan eksplanatoris dalam studi bahasa itu yang mencirikan basis utama, yang bersifat independen pada bahasa apapun (Chomsky 1964) seperti yang dipaparkan oleh Brown (2008:11). Sementara Ferdinand de Saussure mengawali revolusi generatif transformasional mengatakan bahwa bahasa dibagi menjadi langue sebagai system bahasa yang ideal dan diartikan sama dengan kompetensi/competence oleh Chomsky, dan parole adalah bahasa yang digunakan dalam percakapan dan tulisan dan disamakan dengan performance Chomsky. Ferdinand de Saussure memfokuskan pada kajian sosiolinguistinya sedangkan Chomsky pada psikolinguistik. Sementara psikolinguistik Kognitif memfokuskan pada makna, pemahaman dan pengetahuan sebagai data penting bagi studi psikologis berkaitan dengan perilaku manusia.

3. Konstruktivisme (1800-2000) diusung oleh Piaget dan Lev Vgotsky dengan karakteristik menyatukan paradigm-paradigma linguistic, psikologis dan sosiologis. Bagi Piaget 'pembelajaran adalah proses perkembangan yang melibatkan perubahan, pemunculan diri, dan konstruksi, yang masing masing dibangun di atas pengalaman pembelajaran sebelumnya.' (Kaufman, 2004) (dalam Douglas Brown, 2008:13) Brown mengatakan $(2008 ; 13)$ para peneliti yang mengkaji pemerolehan bahasa pertama dam kedua memperlihatkan perspektif konstruksi melalui kajian kajian mengenai wacana percakapan, faktor sosiokultural dalam pembelajaran, dan teori interaksionis. Dapat disimpulkan, perspektif konstruktivis adalah penerus alami kajian berbasis kognitif tentang tata bahasa (grammar) universal, pemrosesan informasi, memori, kecerdasan buatan, dan sistematisasi antarbahasa.

\subsection{Strategi Pembelajaran Bahasa Inggris sebagai Bahasa Kedua dan Aplikasi.}

Brown mengatakan $(2008 ; 143)$ Pakar pakar yang mempelajari penggunaan strategi oleh pembelajar bahasa Inggris sebagai bahasa kedua adalah Michael O'Mallay, Anna Chamot, Bernhart, ElDinary,\& Robin. (1983-1999). Strategi pempelajaran di bagi kedalam 3 kategori:

1. Strategi metakognitif meliputi perencanaan awal, perhatian focus, perhatian selektif, management diri, perencanaan fungsional, pemantauan diri, produksi tertunda dan evaluasi diri.

2. Strategi kognitif meliputi repetisi, melacak ulang, penerjemahan, mengelompokkan, mencatat, deduksi, rekombinas, pencitraan, 
representasi auditoris, kata kunci, kontektualisasi, elaborasi, transfer dan melakukan interferensi.

Tabel 2.1. Tabel Modul Bahasa dan Skill untuk TKT

\begin{tabular}{|l|l|}
\hline $\begin{array}{l}\text { Syllabus } \\
\text { area }\end{array}$ & Example \\
\hline grammar & $\begin{array}{l}\text { parts of speech } \\
\text { the form and use of grammatical } \\
\text { structures }\end{array}$ \\
\hline lexis & $\begin{array}{l}\text { types of meaning } \\
\text { word formation(prefix, suffixes, } \\
\text { compounds, collocation) } \\
\text { word groupings(synonyms, } \\
\text { antonyms, lexical sets, } \\
\text { homophones) } \\
\text { register }\end{array}$ \\
\hline phonology & $\begin{array}{l}\text { word stress, sentence stress, } \\
\text { intonation, connected speech and } \\
\text { phonemes including minimal } \\
\text { pairs } \\
\text { symbols from the phonemic script } \\
\text { (IPA) }\end{array}$ \\
\hline function & $\begin{array}{l}\text { context } \\
\text { levels of formality } \\
\text { appropriacy } \\
\text { a range of functions and their } \\
\text { typical exponents } \\
\text { reading, listening, speaking, } \\
\text { writing, and their subskills }\end{array}$ \\
\hline $\begin{array}{l}\text { Language } \\
\text { skills }\end{array}$
\end{tabular}

3. Strategi sosioafekttif meliputi kooperasi dan pertanyaan untuk klarifikasi.

Aplikasi teori diatas dituangkan dalam Teaching Knowledge Test yang merupakan ilmu pengetahuan bagi pengajar bahasa Inggris sebagai bahasa kedua yang diterbitkan University of Cambridge ESOL Examinations.Teaching Knowledge Test menurut University of Cambridge ESOL Examinations bertujuan mengukur pengetahuan dan konsep berkaitan dengan bahasa, penggunaan bahasa dan latar belakang pengalaman mengajar dan belajar bahasa. TKT merancang test yang dapat diterima, tentang mengajar bahasa Inggris bagi orang asing yang kemudian akan mampu mengajar di arena standar internasional, dan dapat digunakan sebagai ilmu dasar untuk melanjutkan ke jenjang yang lebih tinggi sehingga menunjang peningkatan karier dalam profesinya. TKT mendorong para guru baik guru bahasa atau guru mata pelajaran lain dengan menggunakan bahasa Inggris, untuk mengembangkan profesionalisme.

\section{Tabel 2.2. Tabel Keilmuan Pengengajaran Bahasa Inggris untuk Penutur asing}

\begin{tabular}{|c|c|}
\hline Syllabus area & Examples \\
\hline motivation & $\begin{array}{l}\text { influences motivation } \\
\text { the important of motivation } \\
\text { measures that can } \\
\text { influence motivation } \\
\end{array}$ \\
\hline $\begin{array}{l}\text { Exposure to } \\
\text { language and } \\
\text { focus on form }\end{array}$ & $\begin{array}{l}\text { acquisition } \\
\text { a silent period } \\
\text { the need of L2 learners for } \\
\text { interaction and focus on } \\
\text { form as complements to } \\
\text { exposure }\end{array}$ \\
\hline the role of error & $\begin{array}{l}\text { errors } \mathrm{v} \text { slips interference } \mathrm{v} \\
\text { developmental errors } \\
\text { interlanguage }\end{array}$ \\
\hline $\begin{array}{l}\text { the differences } \\
\text { between L1and } \\
\text { L2 learning }\end{array}$ & $\begin{array}{l}\text { differences in age } \\
\text { differences in the context } \\
\text { of learning }\end{array}$ \\
\hline $\begin{array}{l}\text { learner } \\
\text { characteristics }\end{array}$ & $\begin{array}{l}\text { common learning styles } \\
\text { and preferences common } \\
\text { learning strategies maturity } \\
\text { past learning experience } \\
\text { how learner characteristics } \\
\text { affect learning }\end{array}$ \\
\hline learner needs & $\begin{array}{l}\text { the personal, learning and } \\
\text { (future) professional needs } \\
\text { of learners }\end{array}$ \\
\hline
\end{tabular}

Teaching Knowledge Test terdiri dari tiga modul yang dijabarkan dalam silabus. Silabus modul 1, Language and background to language learning and teaching dijabarkan dalam tiga bagian. Silabus modul 1 Pada bagian 1. Modul pertama menguji pengetahuan terminology dan konsep pengajaran bahasa Inggris secara umum bagaimana menjabarkan bahasa, penggunaannya dan skill bahasa apa yang dikuasai. Bagian1 menjelaskan bahasa dan skill bahasa. Seperti yang terpapar dalam table ini. Bagian 2 modul 1 menguji keilmuan yang melatarbelakangi pembelajaran bahasa Inggris bagi orang asing, bertumpu pada pembelajaran karakter tertentu yang berbeda satu dengan lainnya dalam pembelajaran yang berdampak pada cara pengajar memilih apa dan bagaimana mengajar dikelas baik pada sekelompok 
siswa atau siswa sebagai sosok individu. Candidate need to demonstrate an understanding of concepts and terminology related to the following and their implications for L2 classroom

\section{Tabel 2.3. Tabel Prosedur Belajar Mengajar dan Jenis Kegiatan di Kelas}

\begin{tabular}{|c|c|}
\hline Syllabus area & xamples \\
\hline $\begin{array}{l}\text { Presentation } \\
\text { Techniques and } \\
\text { introductory } \\
\text { activities }\end{array}$ & $\begin{array}{l}\text { introductory activities such } \\
\text { as warmers, lead-ins } \\
\text { common ways of } \\
\text { presenting language }\end{array}$ \\
\hline $\begin{array}{lr}\text { Types } & \text { of } \\
\text { activities } & \text { and } \\
\text { tasks } & \text { for } \\
\text { language } & \text { and } \\
\text { skills } & \\
\text { development } & \end{array}$ & $\begin{array}{l}\text { the design and purpose of a } \\
\text { range of common } \\
\text { comprehension and } \\
\text { production tasks and } \\
\text { activities } \\
\text { frameworks for activities } \\
\text { and tasks } \\
\text {-Presentation Practice and } \\
\text { Production (PPP) } \\
\text {-Task-based Learning } \\
\text { (TBL) Physical Response } \\
\text {-total Phys } \\
\text { (TPR) } \\
\text {-The Lexical Approach } \\
\text {-Grammar-Translation } \\
\text { - test-teach-test } \\
\text {-guided discovery }\end{array}$ \\
\hline $\begin{array}{l}\text { Assessment typ } \\
\text { and tasks }\end{array}$ & $\begin{array}{l}\text { purpose for } \\
\text { (diagnostic, placement, } \\
\text { achievement, formative, } \\
\text { proficiency } \\
\text { methods of assessment } \\
\text { (self, peer, portfolio, } \\
\text { informal and formal } \\
\text { the design and purpose of a } \\
\text { range of assessment tasks } \\
\text { and activities }\end{array}$ \\
\hline
\end{tabular}

Bagian 3 Modul 1 menguji penguasaan fungsi dan ragam pedagogik seorang guru. Bagaimana pilihan pedagogic guru tersebut dalam rangka menyesuaikan karakter murid, proses belajar dan perbedaan antarapembelajaran di L1 dan L2. Bagian modul ini mengji konsep dan keilmuan yang berkaitan dengan prosedur belajar dan mengajar dan jenis kegiatan seperti repeating, eliciting, pairwork. Candidates need to demonstrate an understanding of methods, tasks, activities and terminology related to:
Modul 2 Lesson planning and use of resources for language teaching, dibagi menjadi 2 bagian yakni persiapan dan perencanaan kegiatan mengajar secara effektif dikelas sesuai dengan tujuan dan

\section{Tabel 2.4. Rancangan Mengajar bagi Guru}

\begin{tabular}{|l|l|}
\hline Syllabus area & Example \\
\hline $\begin{array}{l}\text { Identifying } \begin{array}{l}\text { and selecting } \\
\text { lessons aim }\end{array} \\
\text { aims, subsidiary and personal } \\
\text { specification of aims } \\
\text { factors influencing the choice } \\
\text { of aims }\end{array}$ \\
\hline $\begin{array}{l}\text { Identifying the } \\
\text { different } \\
\text { components of } \\
\text { a lesson plan }\end{array}$ & $\begin{array}{l}\text { common sequences- } \\
\text { structural/skills/topic/project }\end{array}$ \\
\hline $\begin{array}{l}\text { Planning an } \\
\text { individual } \\
\text { lesson } \\
\text { sequence or of } \\
\text { lessons }\end{array}$ & $\begin{array}{l}\text { the standard components of a } \\
\text { lesson plan; aims, procedures, } \\
\text { stages, timing, aids, } \\
\text { anticipated problems, } \\
\text { assumptions, interactions, } \\
\text { patterns, timetable fit }\end{array}$ \\
\hline $\begin{array}{l}\text { Choosing } \\
\text { assessment } \\
\text { activities }\end{array}$ & $\begin{array}{l}\text { informal or formal assessment } \\
\text { and related tasks and activities }\end{array}$ \\
\hline
\end{tabular}

kepatutan terhadap kelompok siswa dengan merinci alur kegiatan mengajar dan yang kedua mengenai pilihan bahan ajar dan cara menyajikannya.

Bagian 1 modul 2 silabus, candidates need to demonstrate an understanding of concepts and terminology related to:

Bagian 2 Modul 2 menguji kemampuan pengajar memanfaatkan sumber materi ajar ke dalam lesson plan .candidates need to demonstrate an understanding ofconcepts and terminology related to:

Bagian 1 modul 3 menguji kemampuan pengajar menerapkan fungsi bahasa di dalam kelas, bagaimana guru mengespresikan tujuan pengajar pada murid, mengevaluasi bahasa yang dipakai guru dikelas, menganalisis bahasa murid dan mengkategorikan kesalahan bahasa murid.

Candidate need to demonstrate an understanding of concepts and terminology related to:

Bagian 2 Module 3 menguji pengetahuan fungsi strategi guru dalam mengelola kegiatan di kelas yg efektif (contoh, pola interaksi,ragam kegiatan dan 
pengelolan waktu, teknik memperbaiki kesalahan lisan murid) juga peran guru yang beragam di setiap pembelajaran, sesuai dengan kebutuhan murid dan tujuan belajar mengajar.

Candidate need to demonstrate an understanding ofconcepts and terminology related to:

Tabel 2.5. Cara Mengekslpoitasi Materi Ajar

\begin{tabular}{|l|l|}
\hline & \multicolumn{1}{|c|}{ Example } \\
\hline $\begin{array}{l}\text { Using reference resources } \\
\text { for lesson preparation }\end{array}$ & $\begin{array}{l}\text { the range of } \\
\text { resources } \\
\text { available and } \\
\text { teachers'purpose } \\
\text { for consulting } \\
\text { them }\end{array}$ \\
\hline $\begin{array}{l}\text { The selection and use of } \\
\text { coursebook materials }\end{array}$ & $\begin{array}{l}\text { criteria for } \\
\text { selection, ways of } \\
\text { adopting materials }\end{array}$ \\
\hline $\begin{array}{l}\text { The selection and use of } \\
\text { supplementary materials } \\
\text { and activities }\end{array}$ & $\begin{array}{l}\text { types } \\
\text { supplementary } \\
\text { materials and } \\
\text { activities } \\
\text { reasons for use } \\
\text { how to select and } \\
\text { adapt }\end{array}$ \\
\hline $\begin{array}{l}\text { The selection and use of } \\
\text { teaching aids }\end{array}$ & $\begin{array}{l}\text { types of aids and } \\
\text { their teaching } \\
\text { functions }\end{array}$ \\
\hline
\end{tabular}

Tabel 2.6. Terminologi dan Konsep Bahasa di dalam Kelas

\begin{tabular}{|c|c|}
\hline Syllabus area & Example \\
\hline $\begin{array}{l}\text { The function } \\
\text { commonly used by } \\
\text { the teacher in the } \\
\text { classroom }\end{array}$ & $\begin{array}{l}\text { identification of range } \\
\text { of functions and typical } \\
\text { exponents } \\
\text { appropriacy of common } \\
\text { use(degree of } \\
\text { simplicity of language, } \\
\text { appropriateness of } \\
\text { sequencing, degrees of } \\
\text { formality) }\end{array}$ \\
\hline
\end{tabular}

\begin{tabular}{|l|lr|}
\hline Identifying & identification \\
thefunctions of of & common functions and \\
language used by & typical exponents r \\
learners in the & identification of \\
classroom (this may & $\begin{array}{l}\text { communicative purpose } \\
\text { involve analysis of } \\
\text { language which is not } \\
\text { completely accurate) }\end{array}$ & \\
\hline $\begin{array}{l}\text { Categorising } \\
\text { learners' mistakea }\end{array}$ & $\begin{array}{l}\text { Categorizing types of } \\
\text { mistakes }\end{array}$ \\
\hline
\end{tabular}

Tabel 2.7. Perandan fungsi Guru di Dalam Kelas

\begin{tabular}{|l|l|}
\hline \multicolumn{1}{|c|}{ Syllabus area } & \multicolumn{1}{|c|}{ Examples } \\
\hline $\begin{array}{l}\text { The role of the } \\
\text { teacher }\end{array}$ & $\begin{array}{l}\text { lommon teacher roles and } \\
\text { their functions(e.g } \\
\text { building tapport, } \\
\text { managing the teaching } \\
\text { pace, planning to } \\
\text { introduce variety, catering } \\
\text { for learning factors, } \\
\text { establishing systems for } \\
\text { praise and reward, } \\
\text { establishing rules, routines } \\
\text { and procedures) }\end{array}$ \\
\hline Grouping students & $\begin{array}{l}\text { common classroom } \\
\text { interaction patterns and } \\
\text { their uses and and } \\
\text { grouping of students and } \\
\text { reasons for this }\end{array}$ \\
\hline $\begin{array}{l}\text { methods of oral and } \\
\text { written correction, and } \\
\text { their appropriacy of use }\end{array}$ \\
learners & $\begin{array}{l}\text { the focus and purpose of } \\
\text { feedback } \\
\text { ways of giving feedbacks }\end{array}$ \\
\hline Giving feedback
\end{tabular}

\section{METODE PENELITIAN}

\subsection{Pendekatan Penelitian}

Penelitian ini menggunakan pendekatan kualitatif deskriptif berdasarkan survey studi kasus guru guru Al Azhar yang bersifat deskriptif melalui kegiatan : studi kepustakaan, penelitian lapangan dan analisis hasil pembelajaran ke tiga modul yang terdapat dalam Teaching Knowledge Test dan analisis materi pada modul dua secara rinci. 


\subsection{Partisipan Penelitian}

Pembelajaran TKT diberikan kepada guru guru tingkat SD. SMP dan SMA Al Azhar di beberapa cabang sekolah yang berada di Jakarta. Mereka adalah guru bahasa Inggris, Matematika, Fisika, Biologi, Ekonomi, Sosiologi, Geografi, Agama Islam, dan kimia. Sampai saat ini, diprediksi sudah menyelesaikan empat sampai lima tahapan pelatihan berikut hasil ujian dari Cambridge. Pelatihan ini sudah berjalan sekitar 2 tahun dan masih akan berjalan sampai semua pengajar si sekolah sekolah Al Azhar di Jakarta bahkan di Indonesia, mendapat kesempatan mengikuti pelatihan TKT. Peneliti akan berkonsentrasi pada kelompok pengajar yang telah menyelesaikan dan sedang melaksanakan tahapan TKT.

Jumlah keseluruhan peserta yang telah menyelesaikan pelatihan TKI kurang lebih 60 peserta yang terdiri dari guru SD, SMP dan SMA Al Azhar. Responden yang akan diteliti adalah 47 guru guru telah mendapat sertifikat (angkatan 20092011) dan 11 (angkatan 2012) guru yang yang diberi tugas melakukan materi test yang akan menjadi bahan analisis. Tingkat pendidikan guru $\mathrm{Al}$ Azhar adalah Sarjana S1.

\subsection{Waktu dan Tempat}

Pelatihan TKI berlangsung selama 30 jam dan dilaksanakan dalam satu minggu di lingkungan sekolah Al Azhar pada bulan Juli. Setiap kelompok terdiri dari 12 peserta dan mereka diberi bahan pembelajaran dan latihan sesuai ke tiga modul pada TKT. Penyuluh training TKT adalah seorang Native Speaker yang berkompetent mengajar TKT. diakhir pelatihan mereka mengikuti ujian tiga modul yang diselenggarakan oleh Cambridge dan berkas ujian di kirim dan diperiksa oleh Cambridge di Inggris. Sebulan kemudian Cambridge mengirim hasil ujian per modul ke Indonesia.

\subsection{Metode Pengumpulan Data}

Data yang akan dirujuk adalah Bahan Pelatihan yang diberikan kepada peserta berjudul: The Teaching Knowledge test Course. Cambridge University Press yang dikarang oleh Spratt Mary, Pulverness Alan, William Melanie. 2005. Secara garis besar akan dianalisis apa yang tercakup dalam buku ini. Kemudian hasil ujian TKT akan dianalisis sesuai dengan Kriteria Bench Mark untuk melihat tingkat capaian kemahiran TKT responden. Dari ke tiga modul akan dipilih satu modul yang akan dibahas secara rinci pada tingkat materi yang dihasilkan responden.

\section{HASIL DAN PEMBAHASAN}

\subsection{Analisis The Teaching Knowledge Test}

Materi TKT dirancang secara padat dan lengkap untuk kebutuhan pengajar. Ketiga Modul secara rinci memaparkan penguasaan bahasa, cara mengajar, memahami materi pembelajaran dan cara memahami murid dan mengontrol kelas. Misalnya:

1. modul 1 bagian pertama memusatkan pembelajaran pada bahasa Inggris dilihat dari gramatika yang cukup luas diawali dengan parts of speech yang wajib dipahami dengan baik dan benar sebagai cikal bakal penggunaan bahasa yang baku. Kemudian merancangnya dalam bentuk dan penggunaan struktur gramatikanya.secara berurutan dipaparkan lexis, phonologi dan fungsi bahasa dilihat dari konteks, tingkat formalitas, kepatutan dan ragam fungsi. Setelah memahami apa itu bahasa, dilanjutkan dengan pembahasan language skills yakni,speaking, Reading, listening, writing dan subskill mereka.Fitur fitur bahasa. lisan dan teks tertulis dalam layout, organisasi wacana, accuracy, fluency dan authenticity. Dari tampilan ini terlihat adanya urutan yang berjenjang dari yang mudah hingga sulit.Pada language skills tingkat kesulitannya menjadi beragam. Setiap modul terdiri dari 80 pertanyaan. Jumlah pertanyaan pada bagian pertama modul 1 sebanyak 40 pertanyaan menandakan pada bagian 1 ini cakupan bahasannya sangat luas. Bagian ke dua membahas masalah latar belakang pembelajaran murid seperti motivasi, pengetahuan tentang pemerolehan bahasa I dan 2 dan bentuk bahasa, gaya belajar, strategi pembelajaran, kematangan, kebutuhan murid, dan peran kesalahan berbahasa. Jumlah pertanyaan hanya 15 pertanyaan dan bagian ke 2 modul 1 ini lebih ditujukan kepada guru sepenuhnya daripada bagian pertama yang masih mengenai pemahaman bahasa untuk semua orang. Bagian ke 3 dari modul satu adalah mengenai latar belakang mengajar. Metode apa saja, bentuk pertanyaan apa dan tugas kegiatan seperti apa yang dapat di implimentasikan pengajar/guru.

2. Modul 2 mencakup dua bagian. Pertama Planning and Preparing satu mata ajar secara 
berurutan dengan memperhatikan tujuan pembelajaran, memilih komponen pembelajaran, alur pembelajaran dan cara assesment yang sesuai.Jumlah pertanyaan 40 soal. Bagian kedua mengenai apa, bagaimana dan mengapa menyeleksi dan menggunakan/mengadaptasi materi pembelajaran yang sesuai dengan tujuan pengajaran dan sesuai dengan tingkat kemampuan murid. Pertanyaan 40 soal. Pada bagian ini terlihat bahwa TKI berlaku bagi guru bidang studi apapun baik MIPA ataupun SOSIAL. Guru mendapatkan banyak masukkan sehingga mereka mampu merancang materi sendiri berdasarkan pengetahuan yang dipaparkan TKI. Pembuatan materi sangat penting sebagai inti pengajaran agar mencetak murid murid yang cerdas. Sebagai contoh; guru dipandu untuk mendesign materi yang berwawasan pemikiran kritis sehingga mind set murid akan berkembang ke arah perilaku yang selalu berpikir kritis dan akademik.

3. Modul 3 terdiri dari dua bagian. Pertama menginformasikan bahasa yang digunakan murid dan guru di dalam kelas sesuai dengan ragam fungsi kegiatan dikelas. Bagaiman guru harus menyampaikan instruksi yang jelas dengan menggunakan ketepatan tingkat kesulitan bahasa yang dipilih, mengarahkan murid ke topik bahasan, mengartikan makna topik bahasan yang jelas sampai pada mengkategorikan kesalahan murid dalam belajar. Jumlah pertanyaan 40 soal.Bagian ke dua modul 3 membahas mengenai pengelolaan kelas ketika terjadi kegiatan belajar dan mengajar agar keefektifan kegiatan dapat diterima oleh murid dengan baik. Guru harus selalu peka atas peran mereka sebagai fasilitator pembelajaran dengan menciptakan dua arah komunikasi, mengelola pace pengajaran, merencanakan tugas yang beragam, mendampingi muris ketika dibutuhka, melaksanakan sistim praise and reward, menerapkan peraturan, rutinitas dan prosedur. kenyaman belajar dapt diperoleh dari cara mengelompokkan murid dalam berbagai cara berdasarkan alasan yang tepat. Dalam pembelajaran guru harus menerapkan metode cara mengoreksi baik verbal maupun tertulis, termasuk tujuan dan fokus pada feedback dancara menyampaikannya.

\subsection{Analisis hasil Bench Mark Tiga Modul TKT}

Pada akhir pelatihan TKT, para guru melaksanakan ujian akhir. Hasil ujian tersebut dikirim ke Cambridge dan dikoreksi berapa nilai yang dicapai dari masing masing modul yang kemudian dicantumkan dalam Sartifikat kelulusan. Bench Mark ini merupakan panduan seberapa jauh kemampuan para guru dalam melakukan ujian akhir. Ada empat kelompok penilaian yakni 1 untuk paparan nilai terendah; 2 untuk paparan kemampuan dasar ; 3 untuk paparan cukup baik; 4 untuk paparan sangat baik. Bench Mark yang dikeluarkan Cambridge adalah sebagai berikut berdasarkan modul:

\begin{tabular}{|c|c|}
\hline & $\begin{array}{l}\text { Module 1: Language systems and } \\
\text { background to to language learning and } \\
\text { teaching }\end{array}$ \\
\hline $\begin{array}{c}\text { BAND } \\
4\end{array}$ & $\begin{array}{l}\text { The candidate demonstrates } \\
\text { comprehensive and accurate knowledge } \\
\text { of all areas on the TKT Module } 1 \text { syllabus, } \\
\text { i.e.,language systems and background to } \\
\text { language learning and teaching, He/she } \\
\text { shows familiarity with the full range of } \\
\text { concepts, terminology, practices and } \\
\text { process tested in TKT Module 1, which } \\
\text { relate to describing language and language } \\
\text { skills, factors in the language learning } \\
\text { process and the range of methods, tasks } \\
\text { and activities available to the language } \\
\text { teacher. The candidate is able to relate } \\
\text { existing knowledge to both familiar and } \\
\text { unfamiliar classroom situations }\end{array}$ \\
\hline $\begin{array}{c}\text { BAND } \\
3\end{array}$ & $\begin{array}{l}\text { The candidate generally demonstrates } \\
\text { comprehensive and accurate knowledge } \\
\text { of areas on the TKT Module } 1 \\
\text { syllabus,i.e., language systems and } \\
\text { background to language learning and } \\
\text { teaching, He/she shows familiarity with } \\
\text { most ge of the concepts, terminology, } \\
\text { practices and process tested in TKT } \\
\text { Module 1, which relate to describing } \\
\text { language and language skills, factors in } \\
\text { the language learning process and the } \\
\text { range of methods, tasks and activities } \\
\text { available to the language teacher. The } \\
\text { candidate is generally able to relate } \\
\text { existing knowledge to both familiar and } \\
\text { unfamiliar classroom situations }\end{array}$ \\
\hline BAND & $\begin{array}{l}\text { The candidate demonstrates basic } \\
\text { knowledge of areas on the TKT Module } 1 \\
\text { syllabus,i.e., language systems and }\end{array}$ \\
\hline
\end{tabular}




\begin{tabular}{|l|l|}
\hline 2 & $\begin{array}{l}\text { background to language learning and } \\
\text { teaching, He/she shows familiarity with } \\
\text { some of the concepts, terminology, } \\
\text { practices and process tested in TKT } \\
\text { Module 1, which relate to describing } \\
\text { language and language skills, factors in } \\
\text { the language learning process and the } \\
\text { range of methods, tasks and activities } \\
\text { available to the language teacher. The } \\
\text { candidate is able to relate existing } \\
\text { knowledge to familiar classroom } \\
\text { situations and occasionally to unfamiliar } \\
\text { ones. }\end{array}$ \\
\hline BAND & $\begin{array}{l}\text { The candidate demonstrates restricted } \\
\text { knowledge of areas on the TKT Module 1 } \\
\text { syllabus,i.e., language systems and } \\
\text { background to language learning and } \\
\text { teaching, He/she shows familiarity with a } \\
\text { limited range of the concepts, } \\
\text { terminology, practices and process tested } \\
\text { in TKT Module 1, which relate to } \\
\text { describing language and language skills, } \\
\text { factors in the language learning process } \\
\text { and the range of methods, tasks and } \\
\text { activities available to the language teacher. } \\
\text { The candidate is able to relate existing } \\
\text { knowledge to familiar classroom } \\
\text { situations only. }\end{array}$ \\
\hline
\end{tabular}

Modul 2 merupakan bench mark (ukuran penilaian) dari Perencanaan Pengajaran dan pemanfaatan sumber materi.

\begin{tabular}{|c|l|}
\hline $\begin{array}{c}\text { BAND } \\
\mathbf{4}\end{array}$ & $\begin{array}{l}\text { The } \\
\text { resources } \\
\text { comprehensive and extensive knowledge } \\
\text { of all areas on the TKT Module2 syllabus, } \\
\text { i.e., lesson planning and use of resources } \\
\text { for language teaching. He/she shows } \\
\text { familiarity with the full range of } \\
\text { concepts, terminology, practices and } \\
\text { process tested in TKT Module 2, which } \\
\text { relate to describing general practice in } \\
\text { lesson planning and material use, reasons } \\
\text { for carrying out particular activities in the } \\
\text { classroom and for using particular } \\
\text { resources and materials.The candidate is } \\
\text { able to relate existing knowledge to both } \\
\text { familiar and unfamiliar classroom } \\
\text { situations ans }\end{array}$ \\
\hline $\mathbf{3}$ & $\begin{array}{l}\text { The candidate generally demonstrates } \\
\text { comprehensive and extensive knowledge }\end{array}$ \\
\hline BAND \\
\hline
\end{tabular}

\begin{tabular}{|c|c|}
\hline & $\begin{array}{l}\text { of areas on the TKT Module } 2 \text { syllabus, } \\
\text { i.e., lesson planning and use of resources } \\
\text { for language teaching, He/she shows } \\
\text { familiarity with most of the concepts, } \\
\text { terminology, practices and processes } \\
\text { tested in TKT Module 2, which relate to } \\
\text { general practice in lesson planning and } \\
\text { materials use, reasons for carrying out } \\
\text { particular activities in the classroom and } \\
\text { for using particular resources and } \\
\text { materials. The candidate is generally able } \\
\text { to relate existing knowledge to both } \\
\text { familiar and unfamiliar classroom } \\
\text { situations }\end{array}$ \\
\hline $\begin{array}{c}\text { BAND } \\
2\end{array}$ & $\begin{array}{l}\text { The candidate demonstrates basic } \\
\text { knowledge of areas on the TKT Module } 2 \\
\text { syllabus, i.e., lesson planning and use of } \\
\text { resources for language teaching, He/she } \\
\text { shows familiarity with some of the } \\
\text { concepts, terminology, practices and } \\
\text { processes tested in TKT Module } 2 \text {, which } \\
\text { relate to general practice in lesson } \\
\text { planning and materials use, reasons for } \\
\text { carrying out particular activities in the } \\
\text { classroom, and for using particular } \\
\text { resources and materials. The candidate is } \\
\text { able to relate existing knowledge to } \\
\text { familiar classroom situations and } \\
\text { occasionally to unfamiliar ones. }\end{array}$ \\
\hline $\begin{array}{c}\text { BAND } \\
1\end{array}$ & $\begin{array}{l}\text { The candidate demonstrates restricted } \\
\text { knowledge of areas on the TKT Module } 2 \\
\text { syllabus, i.e., lesson planning and use of } \\
\text { resources for language teaching. He/she } \\
\text { shows familiarity with a limited range of } \\
\text { the concepts, terminology, practices and } \\
\text { procesess tested in TKT Module } 2 \text {, which } \\
\text { relate to general practice in lesson } \\
\text { planning and materials use, reasons for } \\
\text { carrying out particular activities in the } \\
\text { classroom, and for using particular } \\
\text { resources and materials. The candidate is } \\
\text { able to relate existing knowledge to } \\
\text { familiar classroom situations only. }\end{array}$ \\
\hline
\end{tabular}

\begin{tabular}{|c|l|}
\hline & $\begin{array}{l}\text { Module 3: Managing the teaching and } \\
\text { learning process }\end{array}$ \\
\hline $\begin{array}{c}\text { BAND } \\
4\end{array}$ & $\begin{array}{l}\text { The candidate demonstrates } \\
\text { comprehensive and extensive knowledge } \\
\text { of all areas on the TKT Module1 syllabus, } \\
\text { i.e., managing the teaching and learning } \\
\text { process. He/she shows familiarity with the } \\
\text { full range of concepts, terminology, }\end{array}$ \\
\hline
\end{tabular}




\begin{tabular}{|c|c|}
\hline & $\begin{array}{l}\text { practices and process tested in TKT } \\
\text { Module 3, which relate to teachers' and } \\
\text { learners' language in the classrooms and } \\
\text { options available for classroom } \\
\text { management in order to promote learning. } \\
\text { The candidate is able to relate existing } \\
\text { knowledge to both familiar and } \\
\text { unfamiliar classroom situations }\end{array}$ \\
\hline $\begin{array}{c}\text { BAND } \\
\mathbf{3}\end{array}$ & $\begin{array}{l}\text { The candidate generally demonstrates } \\
\text { comprehensive and extensive knowledge } \\
\text { of areas on the TKT Module } 3 \\
\text { syllabus,i.e., managing the teaching and } \\
\text { learning process.He/she shows familiarity } \\
\text { with most of concepts, terminology, } \\
\text { practices and process tested in TKT } \\
\text { Module 3, which relate to teachers' and } \\
\text { learners' language in the classroom and } \\
\text { options available for classroom } \\
\text { management in order to promote learning. } \\
\text { The candidate is generally able to relate } \\
\text { existing knowledge to both familiar and } \\
\text { unfamiliar classroom situations }\end{array}$ \\
\hline $\begin{array}{c}\text { BAND } \\
2\end{array}$ & $\begin{array}{l}\text { The candidate demonstrates basic } \\
\text { knowledge of areas on the TKT Module } 3 \\
\text { syllabus,i.e.,managing the teaching and } \\
\text { learning process.He/she shows familiarity } \\
\text { with some of the concepts, terminology, } \\
\text { practices and process tested in TKT } \\
\text { Module } 3 \text {, which relate to teachers' and } \\
\text { learners' language in the classroom and } \\
\text { options available for classroom } \\
\text { management in order to promote } \\
\text { learning. The candidate is able to relate } \\
\text { existing knowledge to familiar classroom } \\
\text { situations and occasionally to unfamiliar } \\
\text { ones. }\end{array}$ \\
\hline $\begin{array}{c}\text { BAND } \\
1\end{array}$ & $\begin{array}{l}\text { The candidate demonstrates restricted } \\
\text { knowledge of areas on the TKT Module } 1 \\
\text { syllabus,i.e., managing the teaching and } \\
\text { learning process.He/she shows familiarity } \\
\text { with a limited range of the concepts, } \\
\text { terminology, practices and process tested } \\
\text { in TKT Module 1, which relate to } \\
\text { teachers' and learners' language in the } \\
\text { classroom and options available for } \\
\text { classroom management in order to } \\
\text { promote learning. The candidate is able to } \\
\text { relate existing knowledge to familiar } \\
\text { classroom situations only. }\end{array}$ \\
\hline
\end{tabular}

Penjelasan Bench mark sangat lugas mencerminkan kematangan pengelolaan silabus dan cara mengukur kemahiran pada setiap tingkatannya. Dari data yang diperoleh terdapat 44 guru yang telah melaksanakan pelatihan 30 jam dan mendapatkan sertifikat setelah melaksanakan ujian TKT denganhasil sebagai berikut;

44 guru yang sudah mendapatkan sertifikat

$$
\begin{array}{llll}
\text { Modul } 1: 4=0 & 3=11 & 2=28 & 1=3 \\
\text { Modul2 : } 4=0 & 3=9 & 2=28 & 1=6 \\
\text { Modul } 3: 4=0 & 3=8 & 2=30 & 1=5
\end{array}
$$

Kemampuan rata rata guru $\mathrm{Al}$ Azhar berada di band2 yang mencerminkan tingkat kemampuan di level dasar ataubasic, sebagian ada di band 3 yang berarti kemampuan mereka cukup baik.Tidak ada seorang pun yang mendapatkan penguasaan yang sangat baik atau band 4 .

Modul 2 tersulit dilihat dari jumlah ketidak lulusan yang terbanyak daripada modul 1 dan 3. Yakni 6 orang yang verada di level terendah band

\begin{tabular}{|l|c|c|c|}
\hline Nama Peserta & $\begin{array}{c}\text { Modul } \\
\mathbf{1}\end{array}$ & $\begin{array}{c}\text { Modul } \\
\mathbf{2}\end{array}$ & $\begin{array}{c}\text { Modul } \\
\mathbf{3}\end{array}$ \\
\hline Dedy Daryanto & 65 & 48 & 63 \\
\hline Imroh & 64 & 55 & 67 \\
\hline Dyah Larasati & 71 & 64 & 65 \\
\hline Nurlisah & 52 & 44 & 60 \\
\hline Dini Apriyani & 65 & 65 & 65 \\
\hline Ety Kusumawati & 58 & 56 & 63 \\
\hline Wiwik Munawita & 76 & 57 & 61 \\
\hline Siti Maemunah & 44 & 35 & 51 \\
\hline Nasicha & 70 & 58 & 68 \\
\hline $\begin{array}{l}\text { Ridwan Abdul } \\
\text { Malik }\end{array}$ & 45 & 50 & 45 \\
\hline Dasta & 61 & 46 & 62 \\
\hline Nilai Terkecil & 44 & 35 & 45 \\
\hline Nilai Rata-rata & 61 & 52 & 66 \\
\hline Nilai Tertinggi & 76 & 65 & 68 \\
\hline
\end{tabular}

1.Sementara yang mendapat nilai band 2 (basic) terbanyak terdapat di modul 3 sebanyak 30 orang yang menandakan modul 2 lebih slit daripada modul 3 karena hanya28 orang yang tidak lulus.Modul tiga managing the teaching and learning process leih sulit dari modul 2 dilihat dari tingkat kemahiran bernilai baik band 3. Kesimpulan secara umum, urutan tingkat kesulitan adalah modul 2 kemudian modul3 dan modul1. 


\subsection{Analisis Hasil Ujian TKT Modul 1,2 dan 3. Peserta Angkatan 2012}

Para guru angkatan 2012 dianalisis terpisah karena mereka belum menerima srtifikat dari Cambridge. Data yang diambil adalah hasil ujian di kelas dan dari hasil análisis ternyata ada kemiripan dengan temuan yang didapat dari nilai guru-guru yang telah mendapat sertifikat. Informasi di bawah memperlihatkan jumlah jawaban yang benar dari total 80 soal pada setiap modul.

Dari hasil latihan ujian di kelas, angka capaian nilai modul 2 pada nilai terkecil, nilai rata-rata dan nilai tertinggi ternyata paling kecil dari nilai modul 1 dan 3. Maka diasumsi8kan modul 2 lebih sulit dari modul 1 dan 3 .

\subsection{Análisis Tingkat Kesulitan Materi Ujian (soal ujian) Modul 2}

Modul 2 memiliki 80 soal ujian. Tingkat kesulitan soal ujian terlihat dari tingginya jumlah peserta membuat jawaban yang salah terhadap soal-soal tersebut. Setelah dihitung, ada 4 kategori kelompok soal dengan kesalahan terbanyak yang dilakukan guru guru angkatan 2012 yakni:

- Soal no 13 kesalahan dilakukan oleh 12 peserta

- Soal no 20 kesalahan dilakukan oleh 11 peserta

- Soal no 2 kesalahan dilakukan oleh 10 peserta

- Soal no $16,32,37,50,72$ dan 74 kesalahan dilakukan oleh 8 peserta.

Contoh soal no 13.

Mark the correct letter (A-F) on your answer sheet.

No 13. Listen to the pairs of the sentences and say if they are streesed on the same or a different Word.
A. Reading for gist
B. Identifying features of commected speech
C. Listening for gist
D. Listening for specific information
E. Grouping vocabulary according to meaning
F. Focusing on structures

Soal di atas cukup sulit dimengerti oleh guru SD,SMP dan SMA karena menanyakan hal yang sangat teknis dan belum begitu dekat dengan cara belajar di indonesia.
Contoh soal no 20. Padankan catatan seorang guru dengan judul 'lesson plan'

No 20. Learners will remember the form of the present simple lesson plan headings
A. Timtable fit
B. Main or subsidiary aim(s)
C. Personal aims
D. Assuptions
E. Procedures

Pertanyaan di atas membutuhkan latihan yang lama untuk mempraktekan konsep di atas. Pembelajaran bahasa kedua juga harus memperhatikan budaya berfikir masyarakatnya. Dalam TKT tentu budaya Inggris.

\section{KESIMPULAN}

Hasil kegiatan pelatihan Teaching Knowledge Test berhasil memetakan kemampuan mengajar dalam bahasa Inggris para guru Al Azhar. Faktor lainnya adalah temuan mengenai kualitas materi TKT sebagai acuan program SBI. Yang terlihat dalam 3 modul pembelajaran. Hasil temuan penelitian adalah sebagai berikut:

1. Tidak satupun dari semua 44 guru yang mencapai nilai tertinggi pada benchmark band 4

2. Pada umumnya tingkat kemampuan guru guru verada pada tingkat dasar TKT

3. Beberápa guru mendapat nilai cukup

4. Sedikit dari seluruh peserta yang dianggap gagal

5. Pada umumnya penguasaan bahasa Inggris para guru masih perlu ditingkatkan tercermin dengan nilai yang rata rata 61 dalam modul 1

6. Modul 2 dan 3 tergolong sulit namun yang tersulit adalah modul 2 diikuti modul 3 terakhir modul 1

7. Model pembelajaran TKT relatif baru sehingga menjadi sulit

8. Kurangnya latihan membedah buku ajar dalam bahasa Inggris.

9. Memiliki keterampilan yang terbatas pada pemanfaatan sumber bahan ajar.

10. Kemahiran yang terbatas dalam berinteraksi secara efektif dalam bahasa Inggris di dalam kelas.

Saran yang dapat diusulkan untuk memperbaiki kondisi saat ini adalah: 
1. Pelatihan bahasa Inggris harus diselenggarakan secara berkala dalam rangka meningkatkan kemahiran berbahasa Inggris

2. Pelatihan materi TKT harus didiskusikan dalam kelompok guru guru dan dipraktekan di dalam kelas sesuai prosedur

3. Para guru harus sering berdiskusi dalam kelompok mata pelajaran yang diajarkan dan mencari pola pengajaran yang efektif, dengan merujuk pada TKT dalam mata pelajaran tersebut.

4. Para guru secara berkelompok harus terus menerus memanfaatkan kegiatan diskusi guru guru di seluruh dunia melalui www.cambridge.org/elt/tkt

5. Sekolah Al Azhar secara berkala mendatangkan pakar TKT untuk berbagi dan bertukar pikiran membahas ilmu pengajaran yang baru di ranah pendidikan internacional.

\section{DAFTAR PUSTAKA}

[1] Departmen Pendidikan Nasional. 2009 Panduan Penyelenggarann Program Rintisan SMA Bertaraf Internasional. Direktorat Pembinaan Sekolah Menengah Atas:Jakarta.

[2] Harmer, Jeremy.1991. The Practice of english Language Teaching. Longman publishing:New York.

[3] Larsen, Freeman, Diane. 2008. Techniques and Principles in Language Teaching. Oxford University Press: Oxford.

[4] Nunan, David. 1991. Language Teaching Methodology. Prentice Hall: Sydney.

[5] Spratt,Mary and Pulverness, Alan and williams Melanie.2005. The Teaching Knowledge Test Course. Cambridge Press:Cambridge.

[6] www.cambridge.org 